Peter McCullagh aims to assess the scientific validity of proposals to transplant fetal tissue. He believes that 'only if it is established that the new proposal is scientifically valid, is it necessary for society to address the question of whether it is also ethically acceptable' (page 42).

With great care, McCullagh sets out the history of fetal research, citing little known papers dating back to 1878 . He illustrates how scientific proposals evolve from earlier, sometimes discredited, theories, and how many scientific theories, far from being valuefree, are value-laden, causing great benefit or harm. He also shows how once a theory is enshrined in a journal, it can sustain a credibility long after it has been discarded as useless.

Claims that human fetal tissue as transplant material is demonstrably superior to other matter, and has proven therapeutic value, are stringently assessed and are found to be unfounded. McCullagh shows how scientific reports are constructed and publicised in order to gain social approval for what he finds to be unproductive research. He advocates far more critical analysis of scientific claims before they are endorsed by society.

Transplant material is likely to be taken from fetuses aged 12-18 weeks gestation. There is a detailed section on the status of the fetus at this stage, on its aliveness (which is very different from its viability), and on research showing well-developed physical and neurological responses to pain in fetuses of ten weeks' gestation. Fetal tissue for transplantation must be 'harvested' within a few minutes of delivery. Ideally this is by hysterectomy, with the fetus delivered in utero. Drugs which reduce fetal physiological activity need to be avoided. The fetus is therefore in as alive and aware a state as possible when being opened.

McCullagh is concerned that the fetus has none of the protections offered by laws and codes controlling research on humans and animals, although it shares many of their characteristics. One moral principle is that the more weak and helpless a sentient subject is, the more society is responsible to defend it against deliberate harm. McCullagh argues that the harm of fetal research is that it damages society's moral integrity, reducing our collective sensitivity to the claims and needs of weaker beings. His general theory, that such research also harms the researcher, takes on specific meaning in some of the examples, such as severed fetal heads being perfused with a solution in order to measure brain activity. Some research begins in utero, and is therefore likely to be closely associated with medical staff and research students who may also be engaged in obstetric and neonatal care. Laws about dead human donors, forbidding doctors who treated the patient from performing postmortem dissections, do not cover fetal research and tissue transplantation. McCullagh's points need to be considered in relation to women's criticisms of distressingly impersonal treatment of patients in obstetric and neonatal units. Does society want medicine, and medical training, research and promotion requirements, to become ever more highly technical, if this is at the cost of less compassionate medical care for patients? Especially if research continues despite being shown to be costly, harmful and unproductive.

McCullagh gives a clearly argued analysis, for example, of 'good coming out of evil', and of other ethical arguments familiar to readers of this journal. He shows how ethical concepts can be twisted to support dubious activities, and is concerned that fallacies about therapeutic use of fetal material may lead to abortion being accepted, even valued, by society. On consent, he says that it is not necessarily likely that mothers agreeing to abortion will either base their decisions on the interests of the fetus, or be reasonably informed about the proposed research. He dismisses McCormick's notion (about research on children) that the subjects' consent should be assumed because they ought to fulfil moral obligations to society by co-operating in research. McCullagh considers that the aborted fetus owes no moral obligations to society, since it has been accorded none.

Earlier reviews, such as the Peel Report of 1972, are criticised as superficial and often fallacious. McCullagh discusses the shortcomings of present controls and ends by recommending a lengthy, formal, critical enquiry into fetal research. He outlines its tasks which include investigating alternative forms of research.

McCullagh's sensible insistence that ethical discussion must be based on clear, detailed understanding of each scientific proposal raises, I think, three serious problems. First, it implies that research must actually be carried out, in order to provide detailed scientific knowledge, before we can decide whether it is acceptable. Yet many people would argue that certain research is so harmful in principle, that it would be unethical to collect details about it through a practical study. Second, emphasising scientific details tends to result in losing sight of ethical principles in a mass of technical practicalities. Thirdly, the nonscientists' contribution, especially of the women concerned, is liable to be lost in esoteric debates dominated by scientists. This relates to one more problem of this book, its heavy-going style, which gives a sense of a thin lively book struggling to get out of a rather fat repetitive one. It would be unfortunate if the style prevented Peter McCullagh's very important work from reaching the wide audience which needs his information.

PRISCILLA ALDERSON 14 Holyoake Terrace, Sevenoaks, Kent TN13 IPA

\section{By No Extraordinary Means}

Joanne Lynn, 272 pages, USA, \$25, Indiana University Press, 1986

It is no longer controversial to withhold or withdraw technological therapeutic interventions from a patient with no prospect of recovery once it is widely agreed that this is in the patient's best interest. These measures include ventilator support, cardiopulmonary resuscitation, blood transfusion, surgery or chemotherapy for advanced cancer, and antibiotics for intercurren infections. Decisions of this kind can all be regarded as 'letting die' - because when death comes it can be ascribed to pathological developments in the course of illness, albeit those that in other circumstances might have been temporarily alleviated by some medical intervention. Such pathological events may not, however, occur for some time and even when various complications do develop the lack of medical intervention does not always ensure a rapid release for the patient. This is especially so for conditions that are not terminal. These include various types of severe neurological disability such as the vegetative state due to permanent loss of function in the cerebral cortex, advanced motor neuron disease, multiple sclerosis and high quadriplegia. Patients in the vegetative state in particular can survive for many years if nourishment and basic nursing care are provided. Although tubefeeding is a medical measure it is so comparatively simple that it is often 
regarded as part of basic care rather than as an intrusive technology. Indeed such patients are commonly cared for in chronic-care or nursing-home facilities, exceptionally even at home.

In the last decade in the USA the propriety of withholding food and fluid from various types of patient has been frequently discussed in regard to various professional, emotional, ethical and legal issues. The Society for Health and Human Values sponsored a conference in Philadelphia in 1984 and this book comprises a series of essays based on that meeting, edited by Joanne Lynn who writes an introduction and is author of four of the 27 chapters. Dr Lynn has various clinical responsibilities for chronically ill patients and was for some years Assistant Director of the President's Commission for the Study of Ethical Problems in Medicine when it was producing its 1983 report on foregoing life-sustaining treatment.

The book begins with an historical overview of the law and public perceptions by Alex Capron, the lawyer who directed the deliberations of the President's Commission. The procedures for providing food and water are then described, followed by observations by two hospice nurses on the lack of suffering of dying patients who have been allowed to reduce their intake. The last chapter in this initial section reports a small empirical study of physician attitudes. The next nine chapters deal with 'considerations in formulating a moral response', most of them written by philosophers. Matters of public policy are again addressed but from a moral rather than a legal viewpoint. The symbolic significance of giving to eat and drink is fully discussed, and there are chapters from Catholic and Jewish perspectives. One of two chapters co-authored by a physician is basically in favour of withholding food and water when it could be regarded as a form of futile treatment, when there is no possibility of benefit and when to continue feeding would be a disproportionate burden for the patient. These authors also dismiss four moral constraints as inadequate reasons for always providing artificial nutrition and hydration. These are the supposed obligations: to provide ordinary care, to continue any treatment that has once been started, to provide symbolically significant treatment, and to avoid being the unambiguous cause of death. The other physician contribution in this section takes a more cautious and traditional view, reflected in the title 'Killing with
Kindness'. These authors seem overconcerned about the slippery slope argument and about the possible damage to the image of the medical profession if it became known that nontreatment decisions of this kind were frequently made for several groups of patients. Another section deals separately with the different issues raised by specific types of patients newborns, elderly residents in longterm care, patients with permanent loss of consciousness and the competent patient who decides to ask the doctors to withdraw life-support.

The remaining two sections deal with legal issues, six of the nine chapters taking one particular well publicised court case as an example. This is where the American perspective of the book is most obvious, with their much greater readiness to turn to the courts for direction, or for permission to act in the patient's best interest but in a way that might be challenged in such a litigious society. This book as a whole is, however, of considerable relevance for British and European doctors. There is evidence that in Britain certain aspects of practice may soon change in the direction of the greater explicitness that is characteristic of America - even if it does not involve such close involvement of lawyers on a case by case basis. The reason for this is the increasing recognition that doctors cannot alone shoulder decisions that depend more on ethical and societal values than on technical skills or imperatives.

\section{The Patient as Partner}

Robert M Veatch, 241 pages,

Bloomington and Indianapolis, \$27.50, Indiana University Press, 1987

I'm glad I read this book; but not since reading Scott's novels in my schooldays has it taken me so long to get into a story! Which is a pity, because Robert Veatch's huge expertise and experience in this field has much to offer readers across the whole spectrum, from the willing senior doctor or layman taking his turn of duty on his local ethics committee to the expert wrestling with some of the complex issues into which our biomedical sophistication has led us.

The book contains 19 chapters, the majority adapted from the author's previous writings. The purpose of bringing them together is to emphasise Veatch's belief that the solution to the ethical dilemmas of modern medical research is more likely to be found in developing the concept of 'autonomy' than in the more traditional standards of 'consequentialist' ethics, namely finding the best balance between 'doing good' (beneficence) and 'not doing harm'. He argues his case well and in successive chapters develops the themes of 'autonomy' (along with the issue of what informed consent means or should mean) and 'justice', which along with the principles of 'telling the truth', 'keeping promises' and 'not killing' form the basis of what are described as non-consequentialist ethics.

From this basis of theory, Veatch discusses problems relating to the federal regulation of research in the USA, many of which have parallels elsewhere in the world. He finally turns to some specific cases of particular difficulty which he debates from various standpoints.

At first glance, most readers will feel they already respect the 'patient participation' ethic in their routine research and clinical practice. But Veatch's pursuit of his arguments to their logical conclusions creates sometimes uncomfortable realisations of how easy it is to drop this principle when it becomes inconvenient either intellectually or practically. His comments on the semi-randomised clinical trial, on the use of surrogates to determine what is acceptable research method and on the illogicality of excluding record- and survey-based research from the net of informed consent make particularly important reading for all.

Both lay and professional newcomers to ethics committees need a simple and readable text outlining the problems and issues they will meet in their work and the principles they might find helpful for solving them. This book contains the right ingredients and its rigour is an added strength; but I fear there is probably too much of the philosopher's jargon to allow it to become a best-seller amongst the very people it could most help.

J G R HOWIE

Department of General Practice, University of Edinburgh. 